\title{
European perspectives on nitrogen fixation and the application of mineral nitrogen
}

\author{
L.R. MYTTON \\ Institute of Grassland \& Environmental Research, Aberystwyth, UK.
}

\begin{abstract}
An analysis is made of the main factors influencing nitrogen use in the European Union (EU). The Common Agricultural Policy (CAP) is identified as a major factor. A brief explanation is given of its functions and of recent reforms which are aimed at reducing overproduction. These reforms should favour more efficient use of nitrogen. The reasons why this is difficult to achieve are explained and the major factors influencing our ability to balance the nitrogen economies of food production are identified. The interrelationship between these factors is then used to predict the impact of CAP reforms on research, on fertiliser use and on the wider use of legumes.
\end{abstract}

Keywords: Common Agricultural Policy, Europe, farm subsidies, legumes, nitrogen cycle, nitrogen fertiliser, nitrogen fixation, over-production, pollution, soil organic matter

\section{Introduction}

Plants need more nitrogen than any other soil nutrient and soluble nitrogen is one of the largest and commonest nutrient deficiencies in European soils. This is reflected in the fact that the weight of fertiliser nitrogen used in EU agriculture far exceeds the application of any other industrial product (Figure 1; FAO 1994). EU data shows a decline in reliance on legume nitrogen and a substantial increase in dependence on fertiliser $\mathrm{N}$. This is exemplified by UK sales of white clover seed, which for 1971-74 averaged $850 \mathrm{t} / \mathrm{annum}$ but fell by $35 \%$ to $552 \mathrm{t} /$ annum for 1993-95. In 1970 the ratio of ryegrass to clover seed sales was 15:1. By 1995 this had widened to 30:1 (MAFF 1971-75). Over the period 1979 to 1995 the UK dairy herd declined by $18 \%$ from 3.3 to 2.7 million animals but output per animal rose by $16 \%$ from an average of 4621 to 5372 litres/cow/annum (MAFF 1986 \& 1995). It is evident that whilst the use of legumes was declining, unit production was rising. Over little more than two decades the nitrogen economy of grassland made a substantial swing away from clover towards fertiliser nitrogen. This point will be developed fully later.

The problems with clover have been covered extensively elsewhere (Rhodes \& Webb 1993) and will not be reiterated here but it is worth emphasising that the main advantage of fertiliser over clover is that it gives the farmer far better control over the timing and amount of $\mathrm{N}$ that he can apply to his crops. An excellent clover-rygrass pasture in the UK would contain about $30 \%$ clover and yield around $11 \mathrm{t} \mathrm{DM/ha} \mathrm{/annum} \mathrm{(Evans}$ \& Williams 1987). Up to $70 \%$ of this production could be derived from fixed nitrogen (Mytton, unpublished data) setting an upper limit of about $200 \mathrm{~kg} \mathrm{~N}$ fixed per annum. This level of production does not compare well with perennial ryegrass which is capable of yielding 18-20 t DM/ha/annum in response to nitrogen applications of around $400 \mathrm{~kg} / \mathrm{ha}$ (National Institute of Agricultural Botany 1995). The recent economic strategies of the EU have encouraged production and have therfore move the basis of agriculture away from legumes towards fertiliser N. However, there is now growing recognition that the unrestrained use of nitrogen contributes to overproduction and to pollution. Whilst these problems create pressures to use nitrogen more sparingly and more efficiently, there are also political pressures to sustain rural communities and to ensure adequate levels of food production. It will not be easy to meet these conflicting objectives and the difficulties arise out of the complex reactions that occur between the political aims and the way that nitrogen interacts with the various components of the agricultural system

This paper aims to provide brief explanations of the key factors which influence farm nitrogen use in the EU. The explanations are then used to predict the impact of political change on both nitrogen use, on legume use and on legume research.

\section{The economics of fertiliser nitrogen use}

Application of fertiliser is almost wholly determined by profitability. In a free market the problem excessive fertiliser use and over-production would be largely self regulating. Food surpluses would reduce prices which in turn would drive producers to economise on inputs to sustain profitability. One of the major options for reducing the costs of nitrogen inputs should be for growers to move away from fertiliser towards legume nitrogen. This has not occurred in the EU to any great extent because the CAP has subsidised production and created an infinite market for surplus products through the mechanism of intervention buying. It is not surprising 
that Europe's farmers responded vigorously to this policy by bringing as much land as possible into intensive production.

\section{The politics of nitrogen use}

The countries which make up the EU are generally wealthy (Table 1). Consequently, food production is not wholly driven by economic forces. The community also aims to manipulate markets to achieve political objectives. The main targets are self-sufficiency in food production and sustaining farming communities. The mechanisms for achieving this are, subsidised production and the initiation of a principle of Community preference which operates by ensuring that EU products are cheaper than imports. Duties or levies are imposed on competing imports and by the same token EU farm exports are subsidised to enable them to compete on world markets. However, by the end of the 1980s it became increasing obvious that, whatever the political benefits of subsidised food production, the system was sustaining increasingly intensive production and encouraging over-supply. Interestingly, it is also clear that the policy failed to meet the objective of sustaining farming communities. Vast amounts of money were targeted, not at direct farm income but went instead into stockpiling surpluses and then paying subsidies to assist their sales on the world markets. By 1992 the community had stockpiled 20 million tonnes of cereals, a million tonnes of dairy products and three quarters of a million tonnes of beef. The amount spent on farming had risen from ECU 4.5 billion in 1975 to 26 billion in 1988 and then by a further 10 billion in the next 4 years (36 billion in 1992). However, $20 \%$ of the community's farmers got more than $80 \%$ of subsidised income (EU bulletin 5/91 1992).

Table 1: Utilised agricultural land in the EU (mha).

\begin{tabular}{lrrrr}
\hline & 1985 & \multicolumn{1}{c}{1993} & Difference & Change (\%) \\
\hline Belgium & 1.428 & 1.412 & -0.016 & -1.120 \\
Denmark & 2.849 & 2.752 & -0.097 & -3.405 \\
Germany & 12.079 & $17.162^{1}$ & 5.083 & 42.081 \\
Greece & 5.734 & 5.741 & 0.007 & 0.122 \\
Spain & 27.245 & 29.890 & 2.645 & 9.708 \\
France & 31.557 & 30.223 & -1.334 & -4.227 \\
Ireland & 5.707 & 4.440 & -1.267 & -22.201 \\
Italy & 17.883 & 17.215 & -0.668 & -3.735 \\
Luxembourg & 0.128 & 0.127 & -0.001 & -0.781 \\
Netherland & 2.017 & 1.986 & -0.031 & -1.537 \\
Austria & 3.540 & 3.482 & -0.058 & -1.638 \\
Portugal & 4.538 & 3.829 & -0.703 & -15.512 \\
Finland & 2.560 & 2.689 & 0.129 & 5.039 \\
Sweden & 3.580 & 3.359 & -0.221 & -6.173 \\
U.K. & 18.690 & 17.178 & -1.512 & -8.090 \\
\hline
\end{tabular}

1 includes merger of the two Germanys in 1990
The fundamental problem was that support was linked to the amount produced which encouraged intensive production from bigger more efficient units, as reflected in the land use statistics. For example, in the twenty years between 1970 and 1990, France lost about $40 \%$ of its farms and over 2 million people left the land. In the same period Germany lost over $50 \%$ of its farms together with a million farmers and farm workers (Our Farming Future 1993). The development of intensive production is, perhaps, best illustrated by Table 2 which shows the increase in unit-area output for five major commodities in the Netherlands (Our Farming Future 1993). These increases are striking because they were gains made by farmers who were already amongst the most productive in Europe.

Table 2: Increases in Agricultural Yields in the Netherlands.

\begin{tabular}{llcc}
\hline & & 1970 & 1990 \\
\hline Cereals & $\left(\mathrm{t} \mathrm{ha}^{-1}\right)$ & 3.76 & 6.93 \\
Sugar & $\left(\mathrm{t} \mathrm{ha}^{-1}\right)$ & 6.32 & 9.86 \\
Rape & $\left(\mathrm{t} \mathrm{ha}^{-1}\right)$ & 2.91 & 3.00 \\
Milk & $\left(\mathrm{kg} \mathrm{per} \mathrm{cow}^{2}\right)$ & 4170 & 5784 \\
& & $(1960)$ & $(1985)$ \\
Potatoes & $\left(\mathrm{t} \mathrm{ha}^{-1}\right)$ & 26 & 37 \\
\hline
\end{tabular}

The community started to grapple with these problems in the ' 80 s by introducing reforms for all main products (milk in 1984 and the rest in 1988 ). The principle adopted was that if production exceeded a certain fixed level then support payments to farmers were automatically reduced and the reduction applied to all production not just the excess. This system of quotas or stabilisers was only partly successful because commodity levels were set too high. Surpluses still accumulated whilst world prices for key commodities fell causing the cost of export subsidies to rise. In 1992 further reforms were introduced aimed more directly at breaking the vicious circle between high prices and overproduction. The principle adopted this time was one of progressive reductions in support prices to bring key commodity prices nearer to world market prices. This was coupled with reducing the amount of land in arable production (set-aside). Farmers are directly compensated for loss of income but a $15 \%$ reduction in the area of land under certain arable crops is a precondition for receiving support. Set-aside land cannot be used for growing food. Beef prices are also being reduced and farmers compensated by various mechanisms which depend on their herd size and methods of production. Extra premiums are paid for beef produced from grassland (EU bulletin 5/91 1992).

The changes in support in 1988 and 1992 appear to be reflected in the fertiliser statistics. Nitrogen consumption fell by $45 \%$ from a peak of 13.053 million tonnes in 1990 to 7.115 million tonnes in 1993 (Figure 1) 
although it recovered to just over 9 million tonnes in 1994. The data for New Zealand makes an interesting comparison because consumption increased by $270 \%$ from a low of 27,000 tonnes in 1987 to a peak of 100,000 tonnes in 1994 (FAO 1994). The reduction in nitrogen fertiliser used in the EU also reflects a general decline in the amount of land in agriculture (Table 2; Eurostat 1995) but this is a substantially smaller percentage change than is the reduction in fertiliser use. It is difficult to predict the precise effects of the CAP reforms on the role of nitrogen in EC agriculture. There are indications that reforms are having some impact on intensification but it also seems likely that the area of land in agricultural use will continue to decline and the systems which are most vulnerable to being lost are those which rely on more extensive cultivation or lower intensity animal husbandry on open land. However, the new reforms offer increased support to these systems ands this should provide a better basis for more effective use and management of nitrogen resources. Whatever the complexities of these considerations there can be little doubt that there is now a political climate in Europe which is more favourable to the efficient use of fertiliser $\mathrm{N}$ and which should favour a modest increase in the use of legumes and legume $\mathrm{N}$. The challenge for science is to provide farmers with the information and resources to meet these objectives.

Figure 1: Fertiliser consumption in the European Union 19831994.

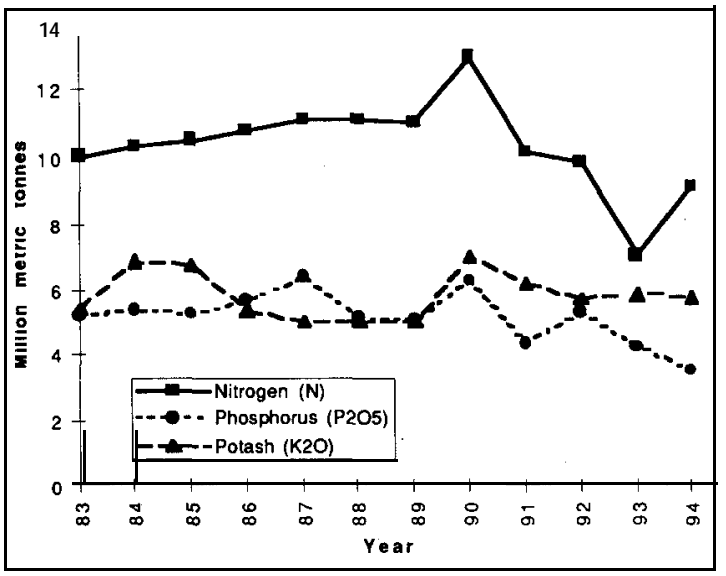

\section{The problem with nitrogen}

\section{Soil organic matter}

Soil nitrogen is an important component of the global N cycle and the soil is a major repository, estimated to contain around $2.4 \times 10^{11}$ tonnes $\mathrm{N}_{2}$ most of which (at least $90 \%$ ) is in organic forms. Although plants are able to utilise simple nitrogenous organic compounds such as amino acids, it is generally accepted that they derive the bulk of their nitrogen from inorganic forms in the soil. Legumes, of course, are able to use atmospheric $\mathrm{N}_{2}$ through the process of symbiotic fixation. The transformation of soil organic nitrogen to inorganic forms (mineralisation) is mediated by soil biota utilising it as a metabolic substrate. This process of biological transformation releases some inorganic nitrogen as ammonia and thence to ammonium which then generally undergoes rapid, biologically mediated, oxidation to nitrate. Nitrate is usually by far the commonest inorganic $\mathrm{N}$ species in the soil. It is not normally adsorbed by soils and is completely water soluble. The circumstances of its production and its solubility make it vulnerable to rapid changes in both amount and distribution in the soil profile as well as to temporal variations in rate of production. Thus, the first problem with nitrogen is that soil organic matter may make a significant but unpredictable contribution to the nitrogen nutrition of crops.

\section{The flow of nitrate through the system}

Soil nitrate is potentially extremely labile. It can go in four directions: it may be incorporated into soil microorganisms, it may be utilised by higher plants, it may be lost in drainage or it may be returned to the atmosphere in a gaseous form. It is probably not as widely recognised as it should be that microbes compete strongly with plants for nitrate. A critical factor in partitioning between these sinks is availability of metabolisable carbon in the soil. In a recent demonstration in the IGER N-fixation laboratory, perennial ryegrass plants were grown in synthetic rooting medium containing ${ }^{15} \mathrm{~N}$ labelled nitrate fertiliser. In addition, the rooting media was either free from microbes or contained a population of soil microbes supplemented with a carbon source. Plants without microbes recovered over $98 \%$ of the nitrate fertiliser whilst those with microbes recovered less than $50 \%$. The bulk of the "missing" nitrogen in the latter treatment was accounted for in increased microbial biomass (Colbourn pers. comm.).

Drainage losses are conditioned by factors such as rainfall, soil texture and structure as well as other cultural conditions. Nitrate uptake by plants depends on factors which influence growth rate, root architecture and the density of roots per unit area of soil. Return of nitrogen to the atmosphere is strongly influenced by nitrate concentrations and by soil oxygen status. High concentrations coupled with anaerobic conditions favour the reduction of nitrate to nitrogen oxides and to elemental N. Under grazing systems, or where animal manure is applied to land, significant amounts of ammonia may also be volatilised from animal wastes. It is evident from this brief summary that the relationships 
between nitrate and the factors controlling its fate are determined by complex interactions which are difficult to understand and control. Thus, the second problem with soluble nitrogen is that regardless of source, be it from animal manure, soil organic matter, atmospheric deposition, symbiotic fixation or fertiliser, crop plants will only secure a proportion of what is available, and that proportion is difficult to predict. The rest will lost to the wider environment or immobilised.

It is evident from this brief summary that the relationships between nitrate and the factors controlling its fate are determined by complex interactions, so that the processes are either poorly understood, difficult to measure or are determined by environmental factors which are not amenable to controls.

\section{Perspectives on symbiotic nitrogen $\&$ fertiliser $\mathbf{N}$}

There is nothing in the above analysis to suggest that the more intensive production systems in Europe will move away from reliance on fertiliser N. Farm income would have to fall substantially or legumes will need to contribute more to the system to change this situation. However, economic and environmental pressures should encourage farmers to be less profligate with fertiliser and we are likely to see research targeting four key areas which impinge upon this. These are; breeding crops for efficient $\mathrm{N}$ capture and use, more research on soil organic matter and its mineralisation and more research on $\mathrm{N}$ losses and greater emphasis on legumes and legume nitrogen. Better understanding of the component parts of the nitrogen cycle will need to be synthesised into predictive models which can then be used to help farmers use nitrogen to better effect. The complexity of these systems suggests that mathematical modelling is the only way of achieving this and existing models will therefore need to be more fully developed. A good example of the modelling approach is provided by Scholefield et al. (1991)

For less intensive systems, especially lower input grassland farming, circumstances look more favourable for clover than they have in the recent past. New, better adapted, cultivars are starting to replacing older varieties and this should provide graziers with a more reliable legume base (Rhodes \& Webb 1993). Better understanding of the nitrogen cycle and its interactions with the components of the sward should also create new opportunities for more successful integration of legumes and fertiliser. Tichen \& Schofield (1992) have evaluated the potential advantages of a more tactical approach to fertiliser $\mathrm{N}$ based on rapid tests for soil mineral $\mathrm{N}$ and have demonstrated significant improvements in animal production coupled with reduced vulnerability to leaching losses. The extension of this type of study into clover based swards holds considerable promise.

\section{References}

EU Bulletin 5/91. 1992. The development and future of the Common Agricultural Policy. Bulletin of the European Communities supplement 5/91. Office for Official Publications of the European Communities, Luxembourg.

Evans, D.R.; Williams T.A. 1987. The effect of cutting and grazing managements on dry matter yield of white clover varieties (Trifolium repens) when grown with S23 perennial ryegrass. Grass and Forage Science 42: 153-159.

FAO. 1994. FAO yearbook - Fertilizer 1994. FAO Statistical Series No. 126. Food \& Agriculture Organisation of the United Nations, Rome.

MAFF. 1970-1995. Seed traders' annual return summary. Ministry of Agriculture, Fisheries and Food, London.

MAFF. 1986. Output and utilization of farm produce in the United Kingdom 1979-1985. Ministry of Agriculture, Fisheries and Food, London.

MAFF. 1986. Agriculture in the United Kingdom 1994. HMSO, London.

National Institute of Agricultural Botany. 1995. Recommended Varieties of Grasses and Herbage Legumes. NIAB, Cambridge.

Our Farming Future. 1993. Commission of The European Communities Directorate General for Audiovisual Information, Communication and Culture Editor: Publications Unit - 200 rue de la Loi, B-1049 Brussels.

Rhodes, I.; Webb, J.K. 1993. Improvement of white clover. Outlook on Agriculture 22 (3): 189-193.

Titchen, N.M.; Scholefield, D. 1992. The potential for a rapid soil mineral $\mathrm{N}$ test for tactical applications of nitrogen fertilizer to grassland. Aspects of Applied Biology 30, Nitrate and Farming Systems. pp. 223229.

Scholefield, D.; Lockyer, D.R.; Whitehead, D.C.; Tyson, K.C. 1991. A model to predict transformations and losses of nitrogen in UK pastures. Plant and Soil 132: $165-177$. 